\title{
Reduction of technogenic load from sludge collectors due to separation and dehydration of the stored material
}

\author{
Olena Bubnova ${ }^{1, *}$, and Oleksandr Shevchenko ${ }^{1}$ \\ ${ }^{1}$ Institute of Geotechnical Mechanics named by N. Poljakov of National Academy of Sciences of \\ Ukraine, 49005, Dnipro, Simferopolska Str., 2a, Ukraine
}

\begin{abstract}
Purpose: the identification of geomechanical problems of mining industry wastes accumulation and substantiation of the ways for their solution with the possibility of processing the watery technogenic feedstock. It has been shown that in order to reduce the technogenic load, it is necessary to reduce the area of land under the waste ponds and the accumulated volumes themselves of mining and enrichment wastes. It has been revealed that the mineral stock, formed from wide grain-size classes with a high content of particles less than $0.2 \mathrm{~mm}$, is dewatered up to $18-$ $22 \%$ by traditional methods and is practically not classified. A mathematical model has been proposed of screening and dewatering kinetics, which takes into account comprehensively the initial distribution of particles and liquid throughout the height of the screened material layer, segregation, mixing, sifting, vibrational transportation features and change in the height of the layer. The use of technology will allow: increase the economic efficiency of enterprises; to expand the feedstock base for construction, coke and chemical industries and power industry; to solve the problems of creating additional containers for storing the wastes; to improve significantly the environmental situation in the mining and processing regions.
\end{abstract}

\section{Introduction}

The mining industry is an industry where the nonwaste production has not yet been achieved and the amount of generated wastes is the largest of all industries. $50 \%$.

Ukraine is the country where the share of the mining industry in total production is 40 -

As a result of imperfections in engineering processes a part of minerals get into wastes, the magnitude of which depends on the type of process and its technological level and the ability of minerals for preparation as well as the complexity of the extraction from the enclosing strata. Also as a rule by-product valuable raw materials (ore as well as nonmetallic) is contained in the sludge (tails) of preparation. As a result in the process of the sludge collector filling and segregation of enrichment wastes particles it takes place

${ }^{*}$ Corresponding author: bubnova@nas.gov.ua 
concentrating of mineral raw materials with specific grain-size composition. Places of technogenic raw materials concentrations represent as an technogenic deposit. Operation life of sludge collector depends mainly on its capacity because it has limited dimensions. Because of the lack of additional space for new sludge collectors for capacity increasing during production process dams are built up or their clearing is performed. Sludge collector clearing gives possibility not only to free up capacity for the storage of newly generated wastes but also increases the resource intensity of resource consumption by wastes reprocessing with extract of mineral components.

The only one solution for the problem of the existence (land withdrawal, respectively) and sludge collectors influence on environmental is their elimination by content extracting. In this case there is a need for the implementation (use) or complete destruction of coal washing wastes that should be extracted.

\section{Methods}

According to the analysis of official statistics data [1] in terms of volumes of solid minerals extraction (Fig. 1), it follows that in the period of $2010-2013$ the volumes of solid minerals production in Ukraine has increased. After a decline in production in 2014, they are increasing again, but have not yet reached the 2013 level.

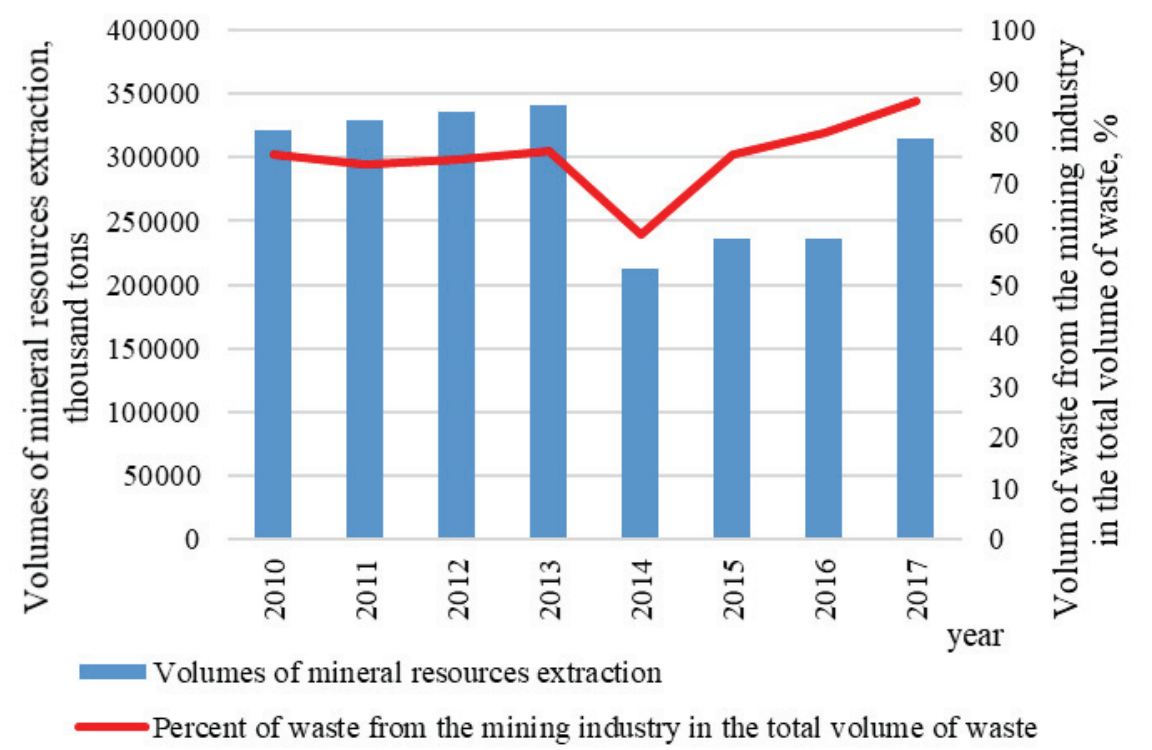

Fig. 1. The volumes of mineral resources extraction (excluding oil and gas) and specific gravity of waste from the mining industry in the total volume of waste in Ukraine for the period of $2010-2017$.

The extraction of all types of solid mineral deposits is invariably accompanied by the formation of wastes in the form of overburden and enclosing rocks located in dumps and waste heaps, slurries and tailings located in ponds. The relative share of mining industry wastes generated annually is $60-85 \%$ in Ukraine. Absolute indicators of the waste volumes generated for the period of 2010 - 2017, according to the official statistics data [1], are shown in Figure 1.

To assess the ratio of the generated waste volumes to the volumes of extracted solid minerals, a graph has been plotted (Fig. 2), which shows that in Ukraine this ratio varies from 0.5 to $1.0 \mathrm{t} / \mathrm{t}$. 


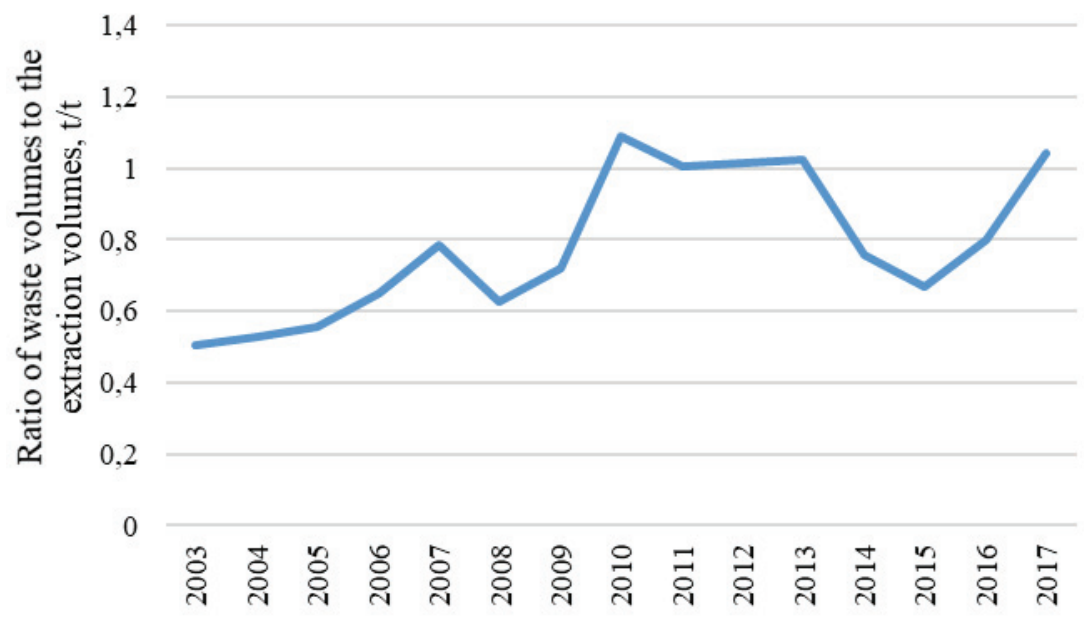

Fig. 2. The ratio of the generated waste volumes to the volumes of extracted mineral resources for the period of $2003-2017$.

The non-uniformity in the ratio of generated wastes to the volumes of mineral resources extraction is explained by the need to carry out stripping operations in certain years in a larger volume in order to prepare reserves for mining. It can also be noted that in Ukraine there is a tendency to an increase in the ratio of waste volumes to extraction volumes.

The waste generation in itself is not a problematic issue, its accumulation is dangerous. So in Ukraine at the beginning of 2018, more than 12.4 billion tons of mining industry wastes have been accumulated. If the specific load of wastes at an average in Ukraine is $2000-3000 \mathrm{t} / \mathrm{km}^{2}$, then in mining areas it reaches up to $8000-20000 \mathrm{t} / \mathrm{km}^{2}$. At the regional level, the bulk of wastes is generated in the Dnipropetrovsk, Donetsk, Zaporizhzhia, Luhansk, Lviv regions [2].

The technogenic objects are displacing and replacing natural ones, the natural balance is disturbed, the natural environment has undergone significant changes (the pollution of atmosphere, water environment and soil, destruction of the geological structure, changes in the properties of rocks and soils, disturbance of the hydrodynamic and hydrochemical regimes of the underground and surface waters, destruction of flora and fauna).

In addition to the disturbance of soils and their withdrawal from agricultural use, the technogenic massifs of mining industry wastes have a negative impact on the surrounding natural environment, the loss of the natural properties of which leads to the earth surface subsidence, landslides, the formation of sinkholes, the development of flooding in the adjacent areas [3].

In Ukraine the most quantity of the existing technogenic objects according to the quantity and quality of their contained minerals can be suitable for industrial development.

Most of the existing technogenic objects are not used and are not recultivated. Their presence on the territory of the country mostly near to the cities causes irreparable damage for the environment and public health. Experience of technogenic deposits development testifies that the cost price of production of their industrial wastes is in 5-15 times less than from mineral raw materials that are extracted by conventional methods. In addition, the mineral raw materials extraction from technogenic objects will significantly reduce the burden on the bowels with maintaining of the produced commodity output volume, reduce the area of land occupied by placement of dumps and sludge collectors, free the capacity for the storage of newly generated production wastes and minerals preparation.

There are no normative documents for the minerals extraction from the sludge collectors. However, scientific developments in this direction are developing [4]. 
In connection with the above, it is proposed to completely extract the contents from sludge collectors and use them as raw materials.

\section{Results and discussion}

To clear the sludge storage as a preliminary mineralogical and granulometric makeup of its content by the square and depth should be studied. It is performed mapping with drawing of the mineral raw materials zones. Ore that was lost in the preparation process can be contained in the heavy coarse grains and can be recovered and recycled in the enriching factory. In the silicate-carbonic compounds sands are accumulated, those that are of coarsegrained and medium sand can be used in the glass and clay industry and pulverescent particles can be used in the ceramic industry. The clarified water can be processed at refineries till the state of fresh water. For practical implementation of the above provisions following technological schemes are substantiated.

Technological scheme of watered sludge storage clearing with a dredger with technogenic raw materials pre- preparation. To solve the problem it has been developed the technological scheme of technogenic mineral raw materials extraction from the watered sludge collector using a dredger with its pre- preparation and industrial water purification at the semiportable complex (Fig. 3).

During the preparation process at the enrichment factory 3 (see Fig. 3) wastes generate - sludge that through slurry pipeline 4, 5 are transported into the sludge collector 1 . In the sludge collector 1 technogenic mineral raw materials deposit which is suitable for the mineral components extraction forms by changing the pulp discharge site 4 and 5 . Place and order of deposits formation are considered in the paper [5].

To increase the capacity of the sludge collector and resource provision of the enterprise sludge from areas of high mineral content 2 , created at the location of pulp discharge in position 4, are extracted by the dredger 6 on a flexible line 7 are given to the semiportable clearing pre- preparation complex 8 . Complex 8 is located on the dam of the sludge collector in immediate proximity to it what makes it possible to reduce the extracted minerals transport distance.

Complex 8 consists of three sections:

- section 8.1 - equipment for pre- preparation of mineral raw materials that were extracted from the sludge collector;

- section 8.3 - technical equipment for process water purification obtained from the mass extracted from the sludge collector after pre- preparation in the section 8.1 and wastes drying (dehydration) in the section 8.4;

- section 8.4 - equipment for wastes dehydration obtained from the sludge prepreparation in the section 8.1 .

Sludge coming through the pipeline 7 is given to the section 8.1 , where by the means of screening, separation and other processes (selected according to the type of mineral component and their washability) is divided into pre- preparated raw materials, process water and wastes. Pre- preparated raw materials are given with the conveyor 8.2 to the enrichment factory 3 or to the consumer (if they satisfy by their quality). Wastes come to the section 8.4 where they are dehydrated, dried and with the conveyor 8.5 are loaded to the dump trucks 9. Wastes can be used for dams dumping of sludge collector 1, for formation of sections in it, for the construction of roads etc. Process water formed by the dehydration of raw materials extracted from the sludge collector in the section 8.1 and pre- preparation wastes from the section 8.4 to the section 8.3 is cleaned up till it satisfies the regulations for drinking water or fishery water using and is transferred to the consumer or is discharged into surface waters (streams) [6]. The salts formed during water clearing are given to the section 8.4 for dehydration and disposal. 


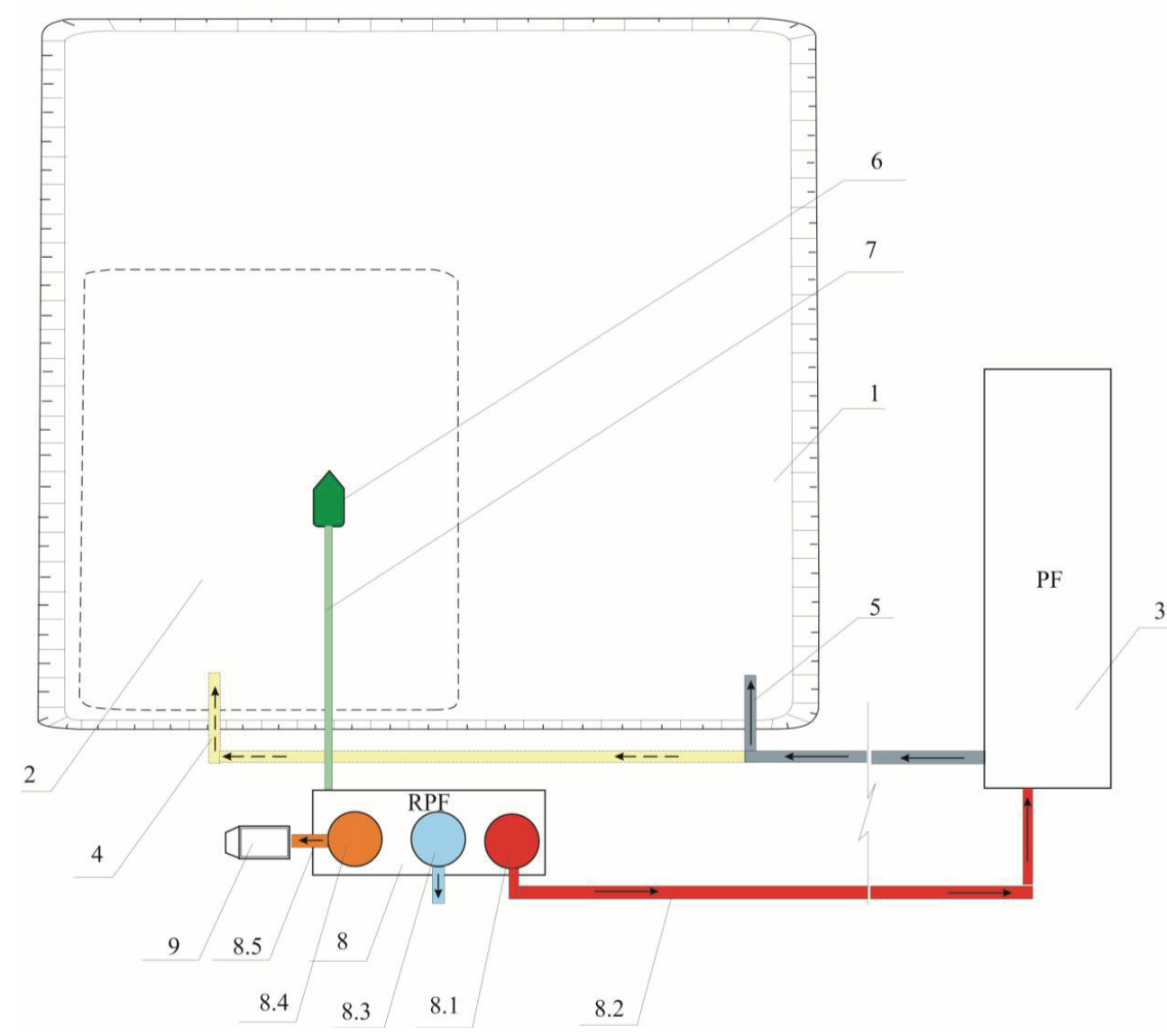

Fig. 3. Technological scheme of technogenic mineral raw materials extraction from sludge collector with its pre-preparation at the semiportable clearing pre-preparation complex: 1 - capacity of the sludge collector; 2 - site of mineral raw materials extraction; 3 - enrichment factory; 4 - pre-position of the pulp discharge; 5 - the current position of the pulp discharge; 6 -dredger; 7 - flexible pipeline; 8 - semiportable cleaning pre- preparation complex; 8.1 - section of sludge pre- preparation; 8.2 - the conveyor; 8.3 - section of water demineralization; 8.4 - section of wastes dehydration and drying; 9 dump truck.

The methods based on the use of water, the so-called wet methods of enrichment, are most widely used in mineral resources enrichment. However, the finished products must have a minimum moisture content - hence, there is a need for dewatering. The similar problems also arise in additional enrichment of wet technogenic feedstock (ore, coal slurries, screenings, etc.), consisting mainly of particles less than $1-5 \mathrm{~mm}$ in size (finegrained feedstock).

Analysis of recent research [7-8], has shown that dewatering of fine and small particles (less than $0.25 \mathrm{~mm}$ in size) causes the greatest difficulties, because, the products formed from them have a highly developed surface, which interacts actively with water, retains significant its amounts due to the highly developed surface of the particles and the acting capillary and electrostatic forces. The porosity and permeability of these media is usually low. With a decrease in the particle coarseness in the products, the binding energy of the liquid with the solid surface increases, in other words, the resistance to water flow increases in the pore space. The higher this energy, the more difficult to separate the liquid. Therefore, it is most difficult to remove water bound by capillary forces (surface tension 
forces). It follows that the known technologies do not provide effective dewatering. In this regard, the problem of moisture removal can be solved by improving the existing technologies.

A mechanical dewatering is the cheapest and most commonly used method [7-8]. Improving the efficiency of removing moisture from fine products by mechanical methods allows to save energy consumed during their thermal bringing to the state of commercial moisture content. For these purposes, a wide variety of equipment is used with different principles of operation: vibrating screens, centrifuges and filters. Vibrating screens are simpler and cheaper than centrifuges and filters. In addition, even in cases when centrifuges and filters are used, vibrating screens are set before them.

At the same time, as the practice has shown [9], the traditional methods make it possible to screen effectively only materials with particle sizes of more than $1 \mathrm{~mm}$, and reduce the moisture content of the finished product to only $18-22 \%$ depending on the coarseness (for comparison, the permissible moisture content during transportation is $8-10 \%$ ). The screening of materials with a coarseness of $0.5-1 \mathrm{~mm}$ by traditional methods does not give high results, and with a particle size of less than $0.2 \mathrm{~mm}$ it is almost impossible.

It is of particular difficulty the processing of wide grain-size classes, when together with dewatering it is necessary to separate fine classes (as a rule, off-test product) and to dewater the finished (oversize) product as much as possible [9].

The author's research results of the waste properties (case study of the construction sands (Liubymivskyi open-pit mine) and coal slurries (Kurakhivska enrichment factory)) indicate the fundamental possibility of obtaining a commercial product having a consumer demand by means of fine classification by coarseness of $0.15-0.2 \mathrm{~mm}$ with a simultaneous dewatering (Figs. 4 and 5), which will allow to reduce the volumes of stored wastes.

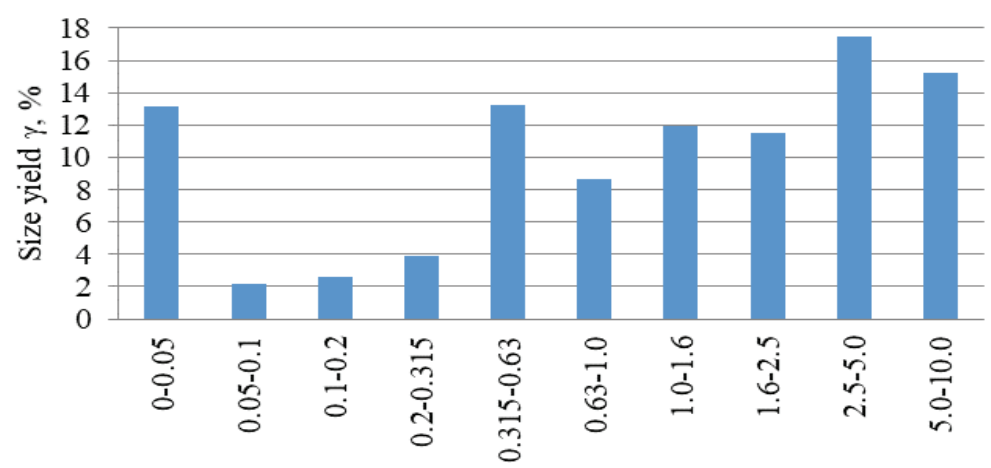

Grain-size classes, $\mathrm{mm}$

Fig. 4. The properties of construction sands (stone screening dust).

At the same time, fine classification according to the specified coarseness with high efficiency for narrow and wide strips of the separated classes of dry bulk materials is a problem. The pulp classification with a solids content according to these classes is even more difficult task, since its solution is complicated by the highly developed surface of fine particles and the acting capillary forces, as well as the additional viscosity of the liquid and clay inclusions dissolved in it [9].

For these purposes, the Ukrainian industry does not produce the serial equipment. At the same time, many authors point at the existing reserves for improving the efficiency of the dewatering process and classification of fine products namely by the way of mechanical impact on them, as the most realizable and relatively inexpensive way [7-8]. 


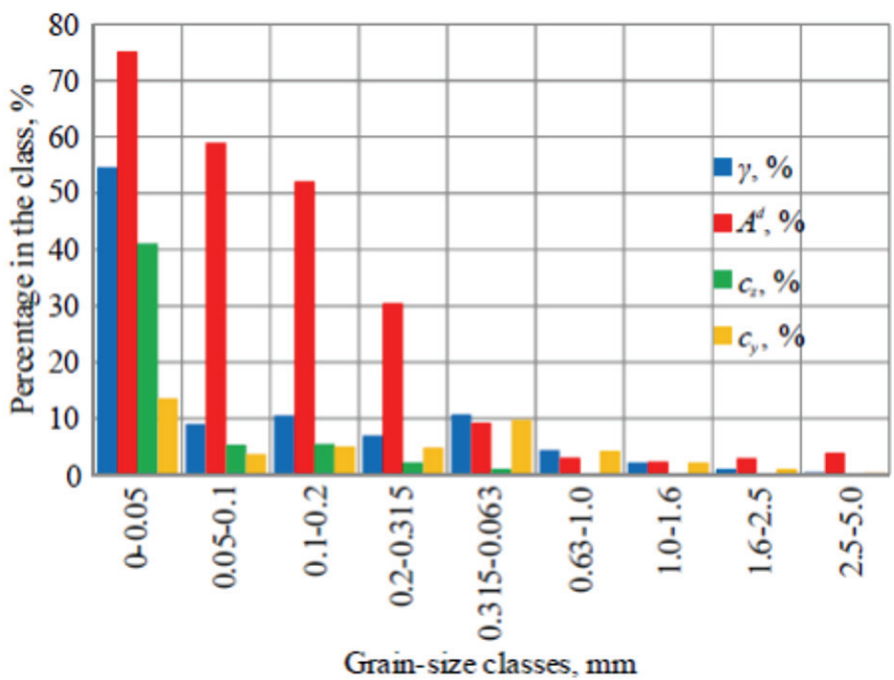

Fig. 5. The properties of coal slurries: $\gamma$ - size yield; $A_{d}-$ ash-content in the class; $c_{z}$ - percentage of ash in the class; $c_{y}$ - percentage of coal in the class.

Hence, the improvement of vibrating screens is of close attention, which will ensure an increase in the efficiency of processing technologies, the quality of feedstock, energy saving and resource saving, as well as a reduction in the harmful effect on the ecology. At thin and ultrafine screening, the removal of liquid requires the substantial energy consumption, since surface tension forces, exceeding the gravity force significantly, resist this process. To overcome these forces on the working surface, accelerations are necessary in the existing serial vibrating screens, which significantly exceed their level. Currently, the developments and individual tests are being carried out in this direction. Institute of Geotechnical Mechanics named by N. Poljakov of National Academy of Sciences of Ukraine has developed a new method of shock-vibrating screening [9], at which, in order to expand the spectrum of impact on the screening surface and the processed feedstock, it is proposed to excite the screening surface with "double" shocks. Initially, the first shock is made, which contributes to the detachment of feedstock from the screening surface and its loosening, then at the flight phase a second shock is made, which provides an additional acceleration for the screening surface, which ensures its cleaning from particles stuck in the holes, as well as menisci rupture of the liquid. It is important to note that when the second shock is applied, the screened feedstock does not prevent the removal of particles and liquid. Additionally, an activator and various disintegrating elements (DE) were used to intensify the screening process [9].

To assess the effectiveness of the new method in shock-vibrating screening, the experiments have been carried out to establish the patterns of moisture content change depending on the structural and operating parameters of the screen and the properties of the feedstock (granulometric composition, narrow and wide grain-size classes, density), the influence of moisture content change on the classification and rational parameters of the screening process with dewatering. The researches were conducted in laboratory conditions on the model of shockvibrating screening. The construction sands of Liubymivskyi open-pit mine were used for the experiments. The author's dependences of change in moisture content $W$ and extraction $\varepsilon$ classes in screened products (oversize and undersize) depending on screening time $t$ in shock-vibrating screening by a new method, are shown in Figure 6.

The application of shock-vibrating screening by a new method made it possible to process the feedstock containing small grain-size classes, which are not classified and 
dewatered with the moisture content of $18-20 \%$ by using traditional methods. The moisture content has been reduced from $30 \%$ to $8-10 \%$, and extraction of the class $0.1 \mathrm{~mm}$ into the undersize product has been increased by $75-80 \%$.

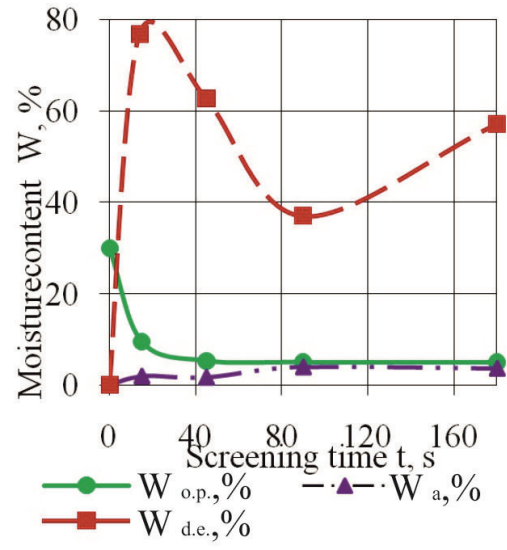

(a)

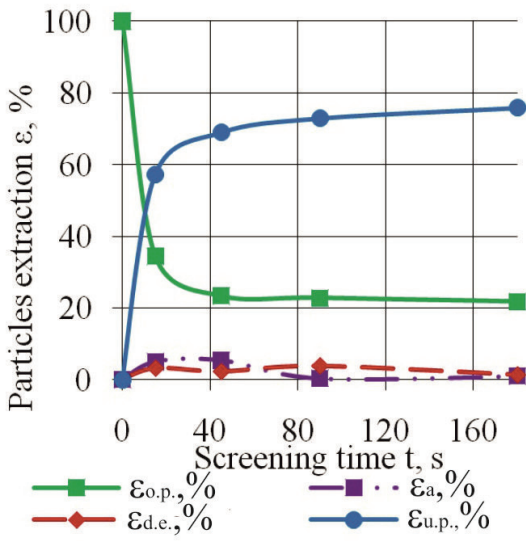

(b)

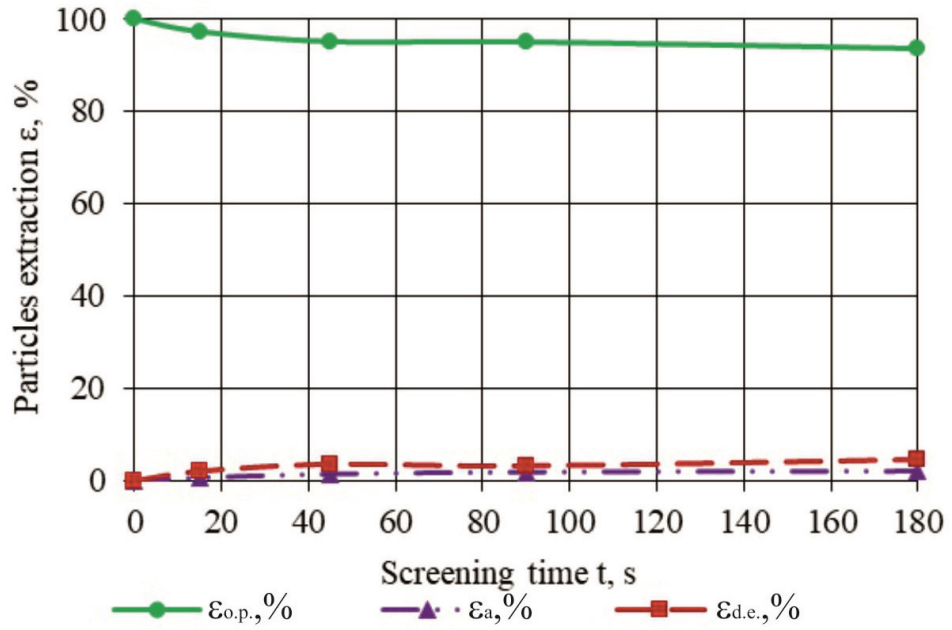

(c)

Fig. 6. Change in moisture content $W$ and extraction of $\varepsilon$ classes in products depending on screening time $t$ : (a) change in moisture content $W$; (b) change in extraction of $\varepsilon$ class $+0-0.1 \mathrm{~mm}$; (c) change in content of $\varepsilon$ class $+0-10.0 \mathrm{~mm}$; $\varepsilon_{\text {o.p. }}$ - extraction into the superlattice product, $\varepsilon_{\mathrm{a}}$ - extraction into the product on the activator, $\varepsilon_{\text {d.e. }}$ - extraction into the product on disintegrating elements, $\varepsilon_{\text {u.p. }}$ - extraction into the undersize product; $W_{\text {o.p. }}$ - moisture content of the shear; $W_{a}$ - moisture content of the product on the activator; $W_{\text {d.e. }}$ - product moisture on disintegrants

The application of shock-vibrating screening by a new method made it possible to process the feedstock containing small grain-size classes, which are not classified and dewatered with the moisture content of $18-20 \%$ by using traditional methods. The moisture content has been reduced from $30 \%$ to $8-10 \%$, and extraction of the class $0.1 \mathrm{~mm}$ into the undersize product has been increased by $75-80 \%$.

Based on the obtained data, the mathematical models have been created for calculating the parameters of the shock-vibrating screen, the dewatering processes of mineral stock and the kinetics of screening and dewatering [10], as well as the numerical experiments have been performed to determine the technological parameters of dewatering and separation by 
coarseness.

The created mathematical models make possible to calculate the performance of screens, screening efficiency and dewatering. Based on the calculation, the technological parameters of screening and dewatering are determined: extraction of particles with a specified coarseness into the undersize product, the undersize product yield rate, the oversize product mass, the liquid mass in the oversize product, and the moisture content of the oversize product. The efficiency of screening is assessed by extraction of the particles with a specified coarseness into the undersize product and moisture content of the oversize product. The novelty of the mathematical model is in taking into account the mutual influence of the classification by coarseness and dewatering.

Having compared the experimental and calculated data results, it was established that they differ by no more than $15 \%$, in other words, the formulas of mathematical models with a confidence coefficient of 0.95 describe adequately the experimental data. These results make it possible by means of a calculation and with the use of initial data to determine rational parameters of the screen and screening process with dewatering at processing of various feedstock.

\section{Conclusions}

Stored wastes development with their further re-processing or use of wastes as a final product (e.g., the building materials production) will provide the company with additional raw materials resources and free capacities.

Full release of the sludge collector capacity makes it possible to return the natural relief and accordingly to restore the natural hydrological processes, its content helps to improve the environmental situation.

It is proposed to subject the wastes of enrichment to a fine classification. It has been revealed that the mineral stock, formed from wide grain-size classes with a high content of particles less than $0.2 \mathrm{~mm}$, is dewatered up to $18-22 \%$ by traditional methods and is practically not classified. It has been confirmed the possibility of processing mineral stock by a new method of shock-vibrating screening based on the obtained dependences, as a result of which the moisture content was reduced from $30 \%$ to $8-10 \%$, and the extraction of the class $-0.1 \mathrm{~mm}$ into the undersize product was increased by $75-80 \%$. The developed mathematical models for calculating the parameters of the shock-vibrating screen, the dewatering processes of mineral stock and the kinetics of screening and dewatering, make possible by means of a calculation and with the use of initial data to determine the rational parameters of the screen and screening process with dewatering at processing of various feedstock.

It is possible on their basis to synthesize a rational process of screening and dewatering, as well as to analyze the existing screens operation in order to identify ways of their modernization. The use of technology, which includes a fine classification in wastes processing, will allow: increase the economic efficiency of enterprises; to expand the feedstock base for construction, coke and chemical industries and power industry; to solve the problems of creating additional containers for storing the wastes; to improve significantly the environmental situation in the mining and processing regions.

\section{References}

1. State Statistics Service of Ukraine. (2018). Retrieved from http://www.ukrstat.gov.ua.

2. Petlovanyi, M.V., Medianyk, V.Y. (2018). Assessment of coal mine waste dumps development priority. Naukovyi Visnyk Natsionalnoho Hirnychoho Universytetu, (4), 
28-35. https://doi.org/10.29202/nvngu/2018-4/3

3. Chetverik, M., Babiy, E., Bubnova, E. (2013). The main technical solutions in rational excavation of minerals in open-pit mining. Annual Scientific-Technical Collection Mining of Mineral Deposits, 173-176. https://doi.org/10.1201/b16354-31

4. Bubnova, O.A. (2017). Klassifikatsiya system razrabotki shlamiv zi shlamonakopychuvachiv. Geo-Technical Mechanics, 132, 105-122

5. Bubnova, Ye.A. (2014). Metodika upravlyaemogo formirovaniya technogennoy zalezhy v shlamonakopitele. Geo-Technical Mechanics, 117, 19-27

6. Levchenko, Ye.S. Opresnenie karernykh, rudnichnykh i shakhtnykh vod - odin iz putey ozdorovleniya rek Ukrauny. Zbirnyk naukovykh prats za rezultatami roboty III mizhnarodnoy naukovo-technichnoy konferentsii. Kryvyi Rih, 19 June 2015, 191 - 193

7. A. Ettmayr, W. Stahl, K. Keller, G. Sauer, Dewatering of fine granular materials by vibrating screens with superposed capillary suction. Developments in Mineral Processing: Proceedings of the XXI International Mineral Processing Congress (2000). https://doi.org/10.1016/s0167-4528(00)80035-6

8. P. Wodzinski, Coal Preparation 23, 4 (2003) https://doi.org/10.1080/07349340302258

9. Lapshin, E.S., Shevchenko, A.I. (2013). Ways of improvement of vibrational segregation and dehydration of mineral raw materials. Naukovyi Visnyk Natsionalnoho Hirnychoho Universytetu, (3), 45-51

10. Lapshin, E.S., Shevchenko, A.I. (2012). Matematicheskoe modelirovanie kinetiki grohocheniya i obezvogivaniya mineralnogo syriya. Naukovo-Tekhnichnyi Zbirnyk Natsionalnoho Hirnychoho Universytetu, 51 (92), 55-64. 